\title{
Synthesis and characterization of new tail-to-tail dimers of bile acids with different spacers
}

\author{
Álvaro Antelo, Mercedes Álvarez Alcalde, Aida Jover, Francisco Meijide, and José \\ Vázquez Tato \\ Departamento de Química Física, Facultad de Ciencias, Universidad de Santiago de \\ Compostela, Avda. Alfonso X El Sabio s/n, 27002 Lugo, Spain,
}

\begin{abstract}
New dimeric steroid-based surfactants derived from $3 \alpha, 7 \alpha, 12 \alpha$-trihydroxy-5 $\beta$ cholan-24-amine (steroid residue) and isophthalic acid, 5,5'-biisobenzofuran-1,1',3,3'carboxylic acid and succinic acid (spacers) were synthesized and structurally characterized by NMR techniques. The first spacer was also employed to synthesize the dimer corresponding to the $3 \alpha, 12 \alpha$-dihydroxy-5 $\beta$-cholan-24-amine residue. In all cases the steroid residues are tail-to-tail linked through amide bonds with the spacers.
\end{abstract}

\section{Introduction}

Dimeric surfactants represent a very interesting type of tensioactive compounds that comprise two surfactant-like moieties connected by a bridge of varying nature (flexible or rigid) and length. When the linking is performed at or near their head groups, the resulting dimers are known as gemini. This kind of compounds has recently been object of increasing study in view of their enhanced tensioactive properties compared with those of monomeric surfactants, as well as their phase behaviour. ${ }^{1,2}$

Compared with typical alkyl-chain surfactants, ${ }^{3}$ bile salts present different surface properties, a fact directly related to their structure, namely their facial amphiphilicity. Although the transference of this peculiar characteristic to the gemini structure could lead to new tensioactive properties and aggregation behaviours, only few examples of gemini surfactants formed by two bile acid residues linked in a tail-to-tail

\footnotetext{
${ }^{1}$ In, M.; Zana, R. Journal of Dispersión Science and Technology 2007, 28, 143-57.

${ }^{2}$ Hait, S. K.; Moulik, S. P. Curr. Sci. 2002, 82, 1101.

${ }^{3}$ P.P. Nair, D. Kritchevsky, The Bile Acids; Physiology and Metabolism vol. 1, Plenum Press, New York, 1971 Chapt. 8.
} 
way have been published. ${ }^{4,5,6,7,8}$ In view of the results obtained by a previous study of the host-guest interactions between the tail-to-tail dimers presented here and ibuprofen which are published in other communication at ECSOC13, the new gemini surfactants were synthesized and are now available for experimental studies.

The natural bile acids ( $\underline{1}$ and $\underline{2})$, the precursors of the dimers ( $\underline{3}-\underline{7})$ and the synthesized tensioactive derivatives $(\underline{8}-\underline{11})$ are compiled in figure 1 .
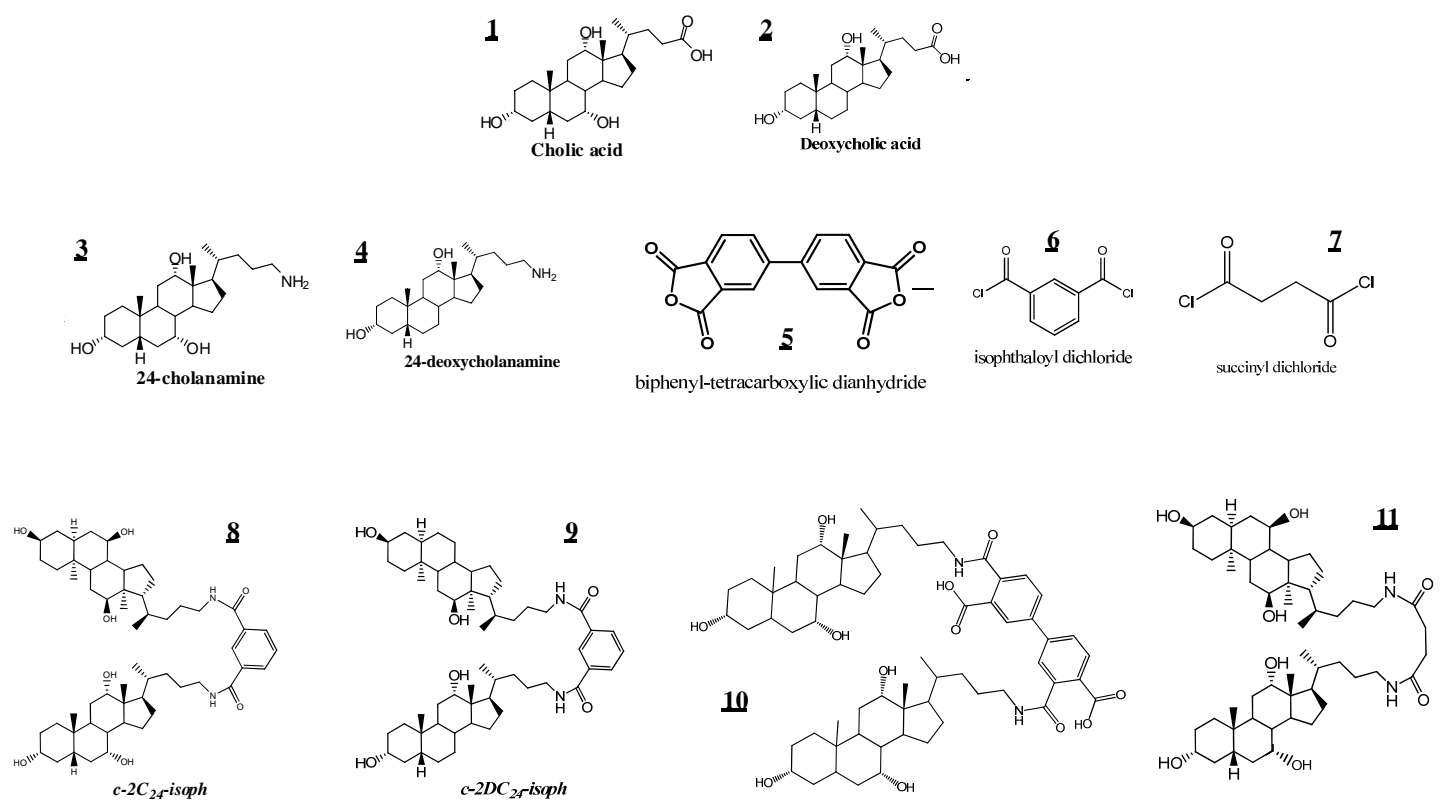

Figure 1.- Natural bile acids ( $\underline{1}-\underline{2})$, precursors ( $\underline{3}-\underline{7})$ and dimers synthesized ( $\underline{8}-\underline{11})$.

\section{Experimental section}

\section{Synthesis.}

The synthesis of the precursor steroid residues (24-cholanamine and 24deoxycholanamine) from the corresponding natural bile acids are sketched in Scheme 1, following well described routes. ${ }^{8,9}$

\footnotetext{
${ }^{4}$ McKenna, J.; McKenna, J. M.; Thornthwaite, D. W. J. Chem. Soc., Chem. Commun. 1977, 809.

${ }^{5}$ Li, Y.; Dias, J. R. Chem. Rev. 1997, 97, 283.

${ }^{6}$ Ronsin, G.; Kirby, A. J.; Rittenhouse, S.; Woodnutt, G.; Camilleri, P. J. Chem. Soc., Perkin Trans. 2 2002, 13026.

${ }^{7}$ M. Álvarez Alcalde, A. Jover, F. Meijide, L. Galantini, N. V. Pavel, A. Antelo and J, Vázquez Tato, Langmuir, 2008, 24, 6060 .

${ }^{8}$ Alcalde, M. A.; Antelo, A.; Jover, A; Meijide, F., Tato, J. V. $12^{\text {th }}$ INTERNATIONAL ELECTRONIC CONFERENCE ON SYNTHETIC ORGANIC CHEMISTRY.

${ }^{9}$ Fini, A.; Fazio, G.; Roda, A.; Bellini, A. M.; Mencini, E.; Guarneri, M. J. Pharm. Sci. 1992, 81, 726.
} 


\section{Scheme 1}
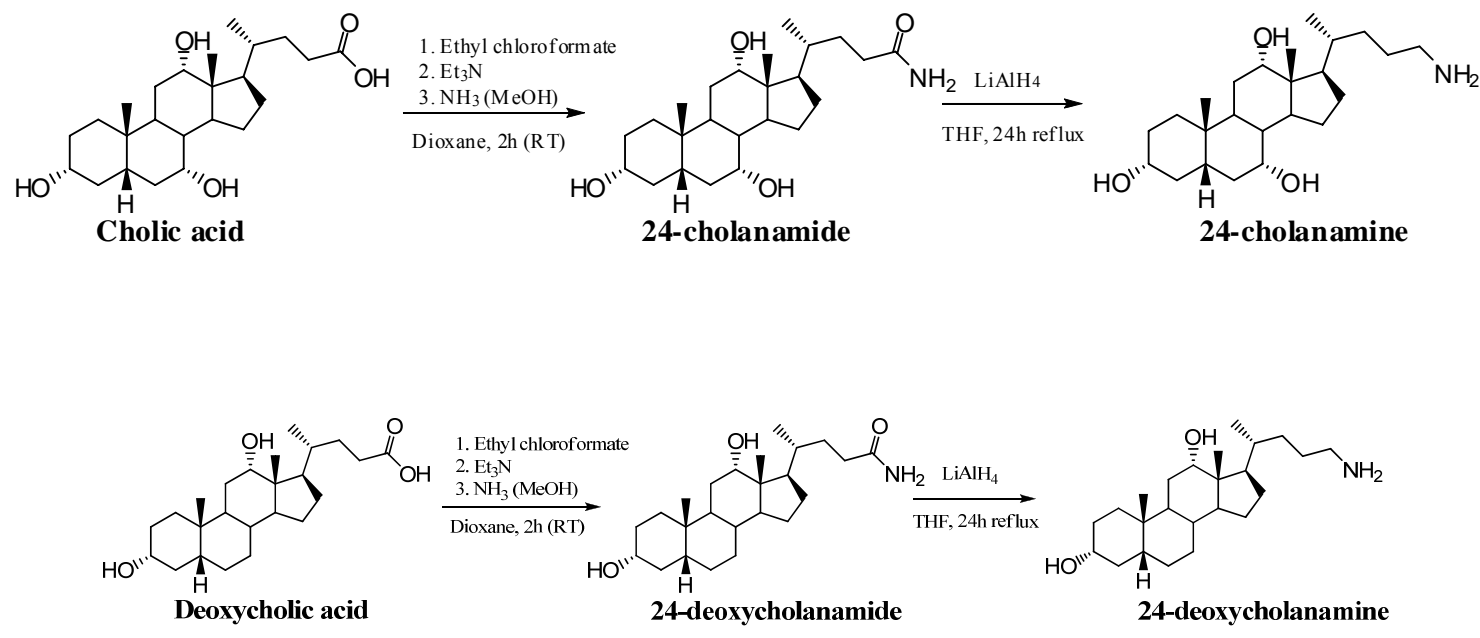

The synthetic strategies for obtaining the gemini surfactants are resumed in Scheme 2 and commented on in the following paragraphs.

\section{Scheme 2}

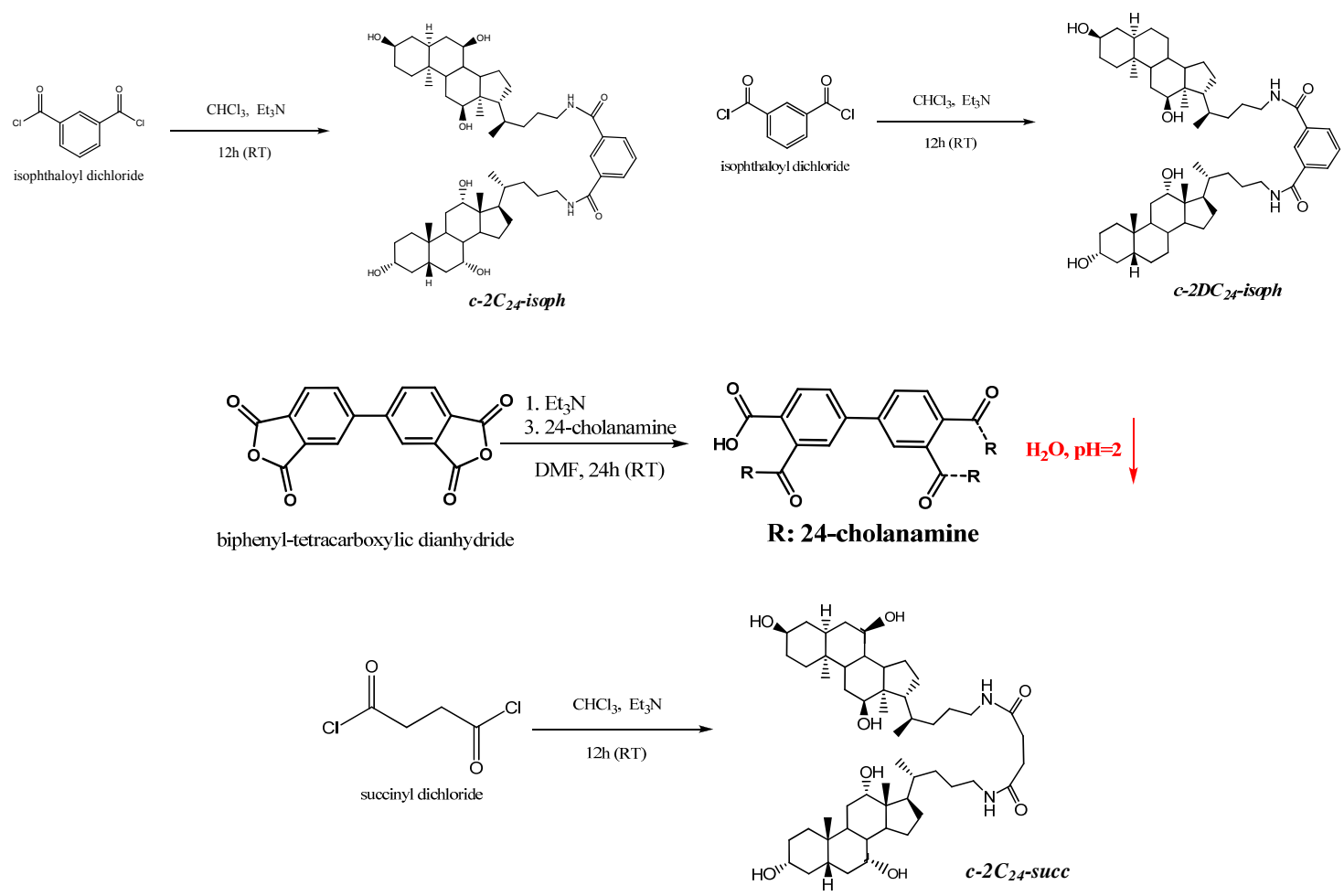

$\underline{8}$ and $\underline{9}$ - 24 -Cholanamine $(0.5117 \mathrm{~g}, 1.3 \mathrm{mmol})$ or 24-deoxycholanamine $(2.0 \mathrm{~g}$, $5.4 \mathrm{mmol}$ ) were dissolved in a mixture of $25 \mathrm{~mL}$ of dried $\mathrm{CHCl}_{3}$ and $1 \mathrm{~mL}$ of TEA. After $30 \mathrm{~min}$, the solutions were cooled at $0^{\circ} \mathrm{C}$ and a solution of isophthaloyl dichloride 
$(0.1188 \mathrm{~g}, 0.59 \mathrm{mmol})$ in $5 \mathrm{~mL}$ of dried $\mathrm{CHCl}_{3}$ was added dropwise with stirring. After $90 \mathrm{~min}$ the ice bath was removed and the reaction was maintained for $12 \mathrm{~h}$ at r.t. ( $\underline{8}$ ) or at $50^{\circ} \mathrm{C}(\underline{9})$. The solvent was then evaporated under vacuum. Finally, the products were purified by column chromatography (silica gel 70-230 mesh; eluent 8:2 ethyl acetate:methanol, $\mathrm{R}_{\mathrm{f}}=0.5$ and 0.72 , respectively for $\underline{8}$ and $\left.\underline{9}\right)$. Overall yields: $50 \%(\underline{8})$, $75 \%(\underline{9})$.

10.- Biphenyl tetracarboxylic dianhydride $(0.26 \mathrm{~g}, 1 \mathrm{mmol})$ was dissolved in 4 $\mathrm{mL}$ of dried DMF. Solution was cooled at $0^{\circ} \mathrm{C}$ and a solution of $3 \alpha, 7 \alpha, 12 \alpha$-trihydroxy$5 \beta$-cholan-24-amine $(1.2 \mathrm{~g}, 3.1 \mathrm{mmol})$ and triethylamine $(1.0 \mathrm{~mL}, 7.20 \mathrm{mmol})$ in $8 \mathrm{~mL}$ of dried DMF was added. After 15 min the ice bath was removed and the reaction was maintained for $24 \mathrm{~h}$ at r.t. The solvent was evaporated under vacuum. Then $5 \mathrm{~mL}$ of methanol were added and washed twice with water $(\mathrm{pH}=2)$ where the compound precipitates in its diacid form. Then the precipitate was filtered and dried in a vacuum oven. Finally the product was purified by column chromatography (silica gel 70-230 mesh; eluent 7:3 ethyl acetate:methanol, $\left.\mathrm{R}_{\mathrm{f}}=0.69\right)$. Overall yield $46 \%$.

11.- 24-Cholanamine $(0.4 \mathrm{~g}, 0.36 \mathrm{mmol})$ was dissolved in a mixture of $25 \mathrm{~mL}$ of dried $\mathrm{CHCl}_{3}$ and $1 \mathrm{~mL}$ of TEA. After $30 \mathrm{~min}$, the solution was cooled to $0^{\circ} \mathrm{C}$ and a solution of succinyl dichloride $(0.03 \mathrm{~g}, 0.17 \mathrm{mmol})$ in $5 \mathrm{~mL}$ of dried $\mathrm{CHCl}_{3}$ was added dropwise with stirring. After $90 \mathrm{~min}$ the ice bath was removed and the reaction was maintained for $12 \mathrm{~h}$ at r.t. The solvent was evaporated under vacuum. Finally the product was purified by column chromatography (silica gel 70-230 mesh; eluent 8:2 ethyl acetate:methanol, $\left.\mathrm{R}_{\mathrm{f}}=0.56\right)$. Overall yield $70 \%$.

\section{Structural characterization.}

Identity of compounds was confirmed by ${ }^{1} \mathrm{H}(300 \mathrm{MHz}),{ }^{13} \mathrm{C}(75 \mathrm{MHz}) \mathrm{NMR}$ and DEPT-135 (75MHz) experiments carried out in a Brucker AC 300 spectrometer (Figures 2-12). 


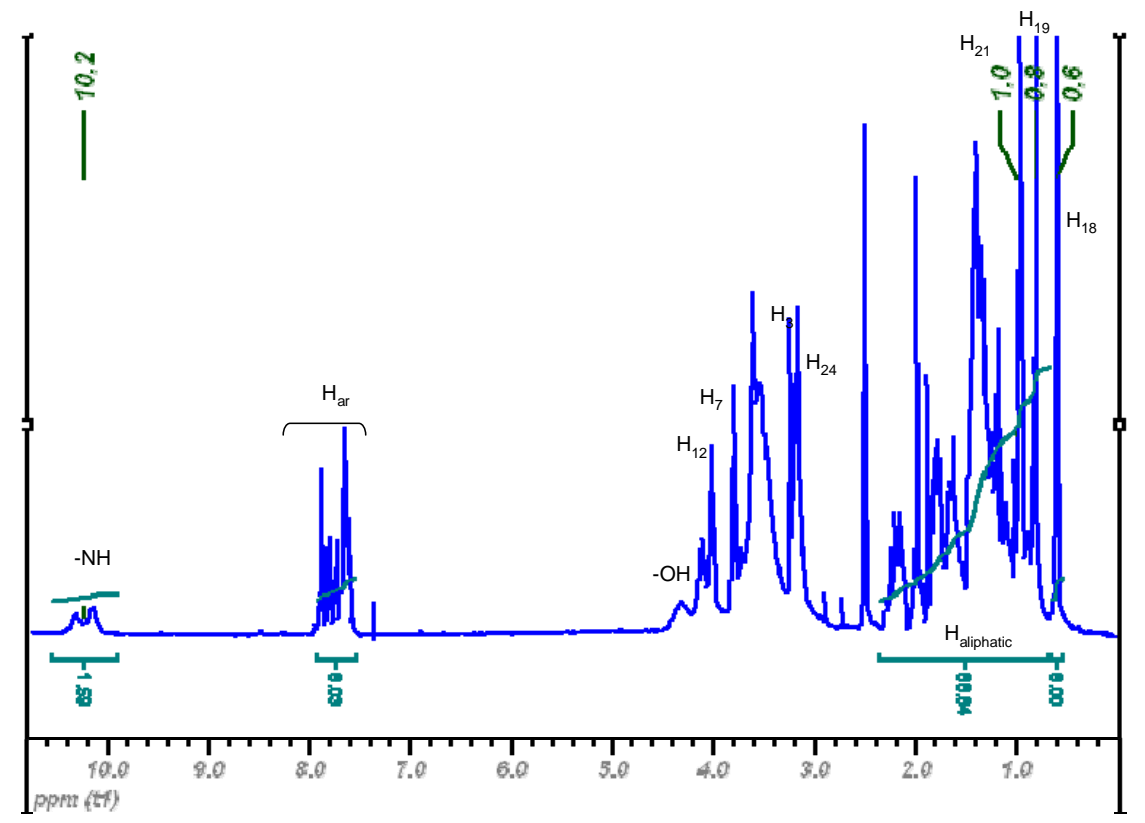

Figure 2.- ${ }^{1} \mathrm{H}$ spectrum of $\underline{10}$ in DMSO- $\mathrm{d}_{6}$.

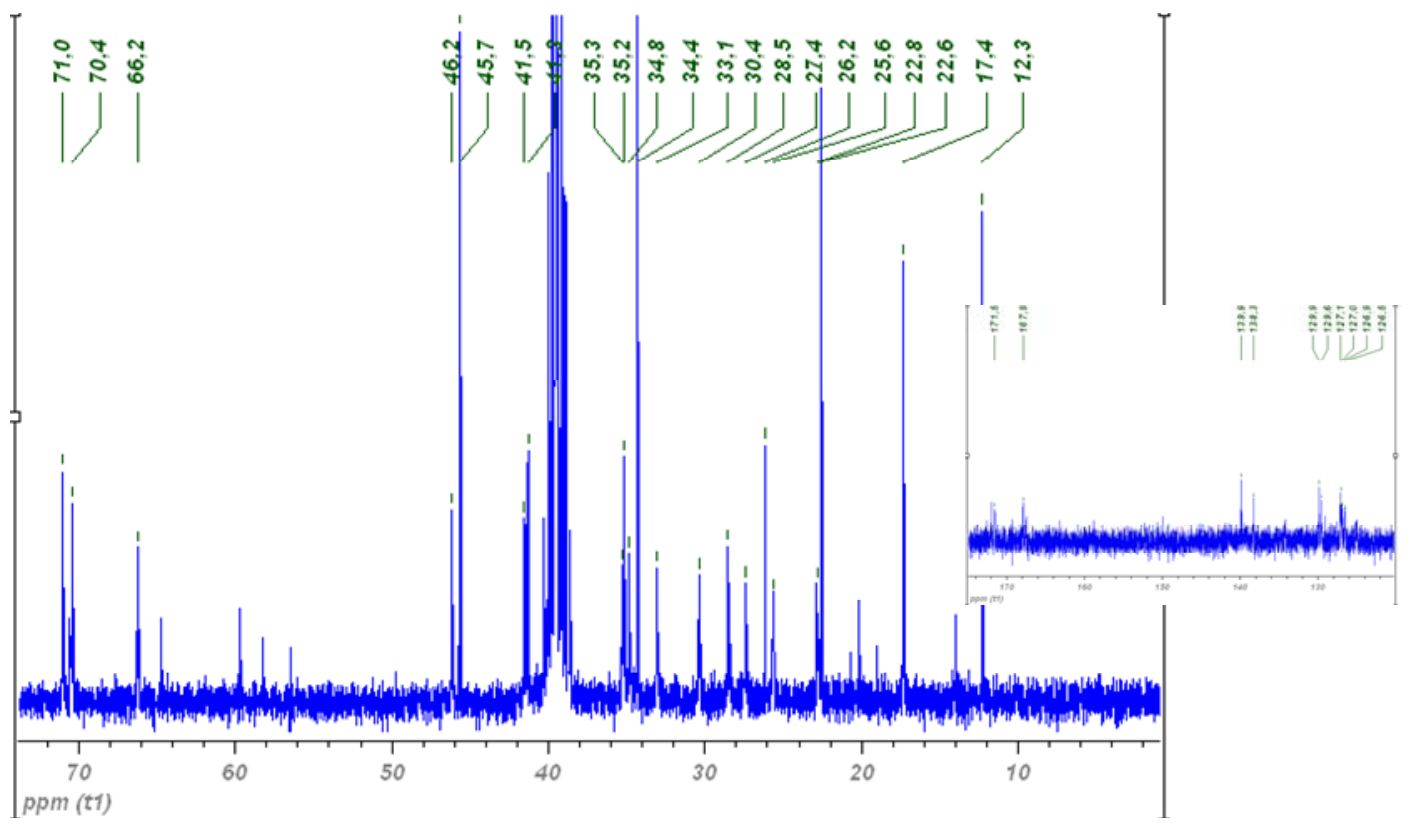

Figure 3.- ${ }^{13} \mathrm{C}$ spectrum of $\underline{10}$ in DMSO- $\mathrm{d}_{6}$. 


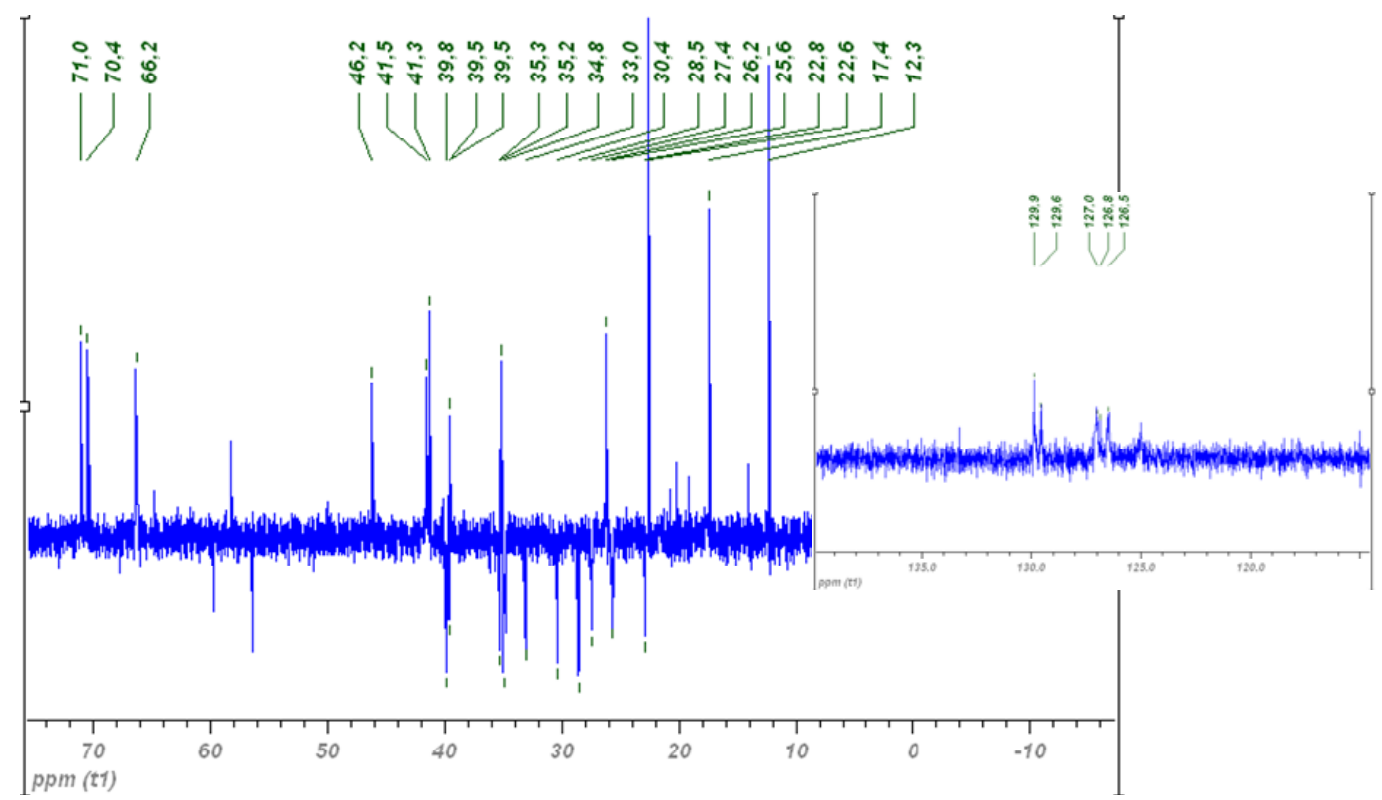

Figure 4.- DEPT-135 spectrum of $\underline{10}$ in DMSO- $\mathrm{d}_{6}$.

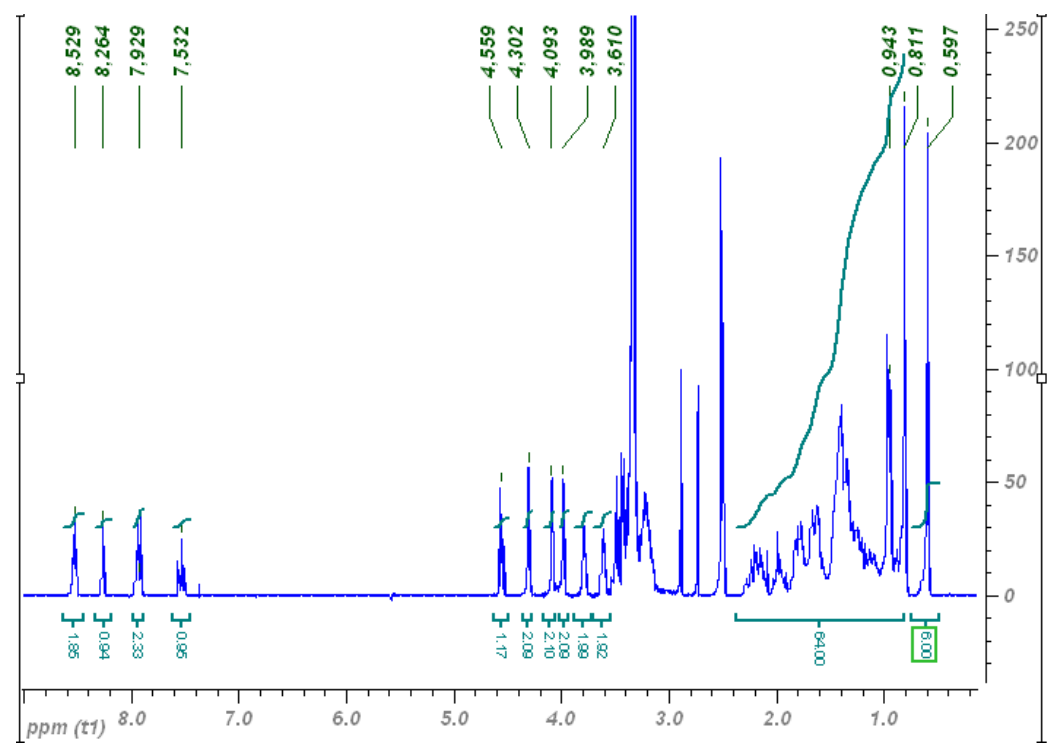

Figure 5.- ${ }^{1} \mathrm{H}$ spectrum of $\underline{8}$ DMSO- $\mathrm{d}_{6}$. 

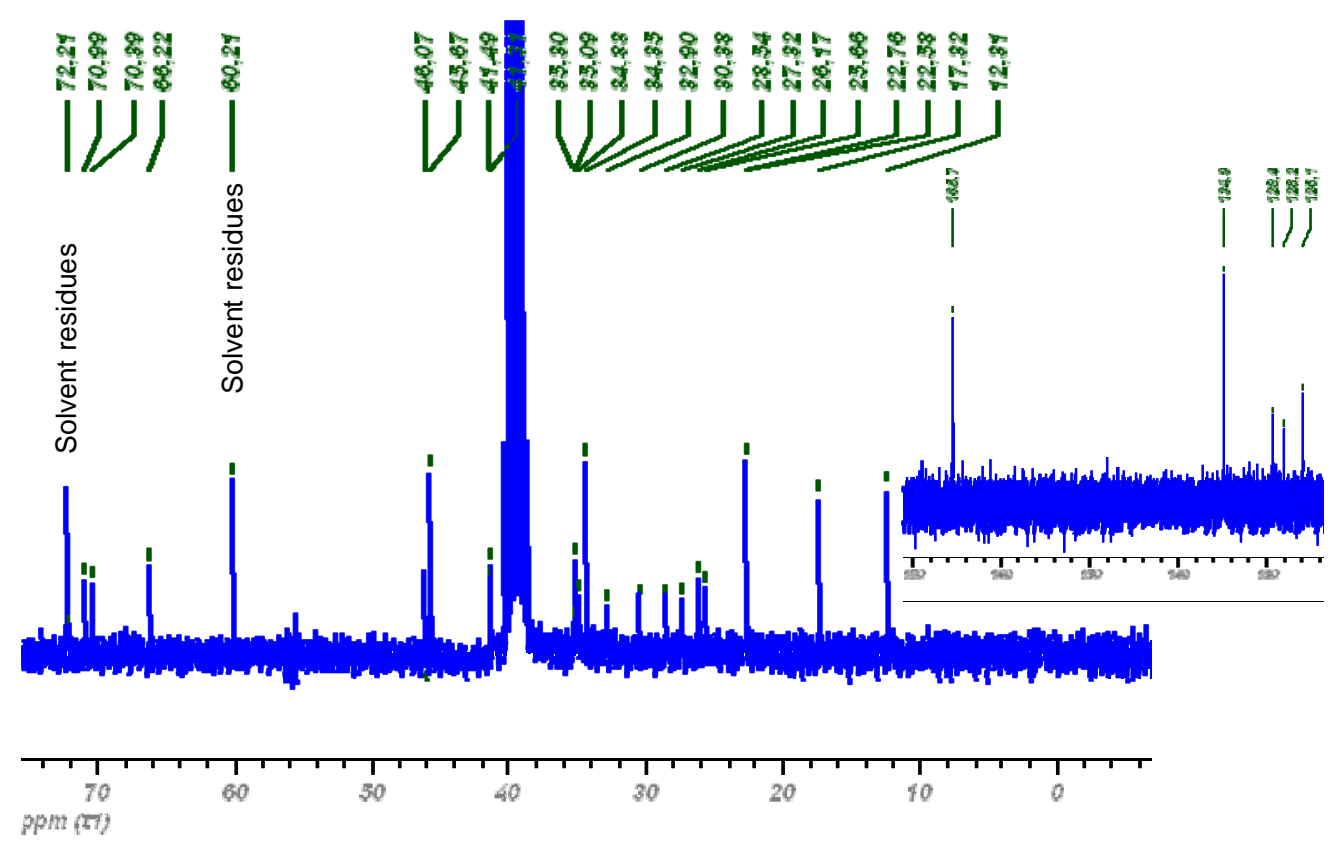

Figure 6.- ${ }^{13} \mathrm{C}-\mathrm{NMR}$ spectrum of $\underline{8}$ in DMSO-d $\mathrm{d}_{6}$.

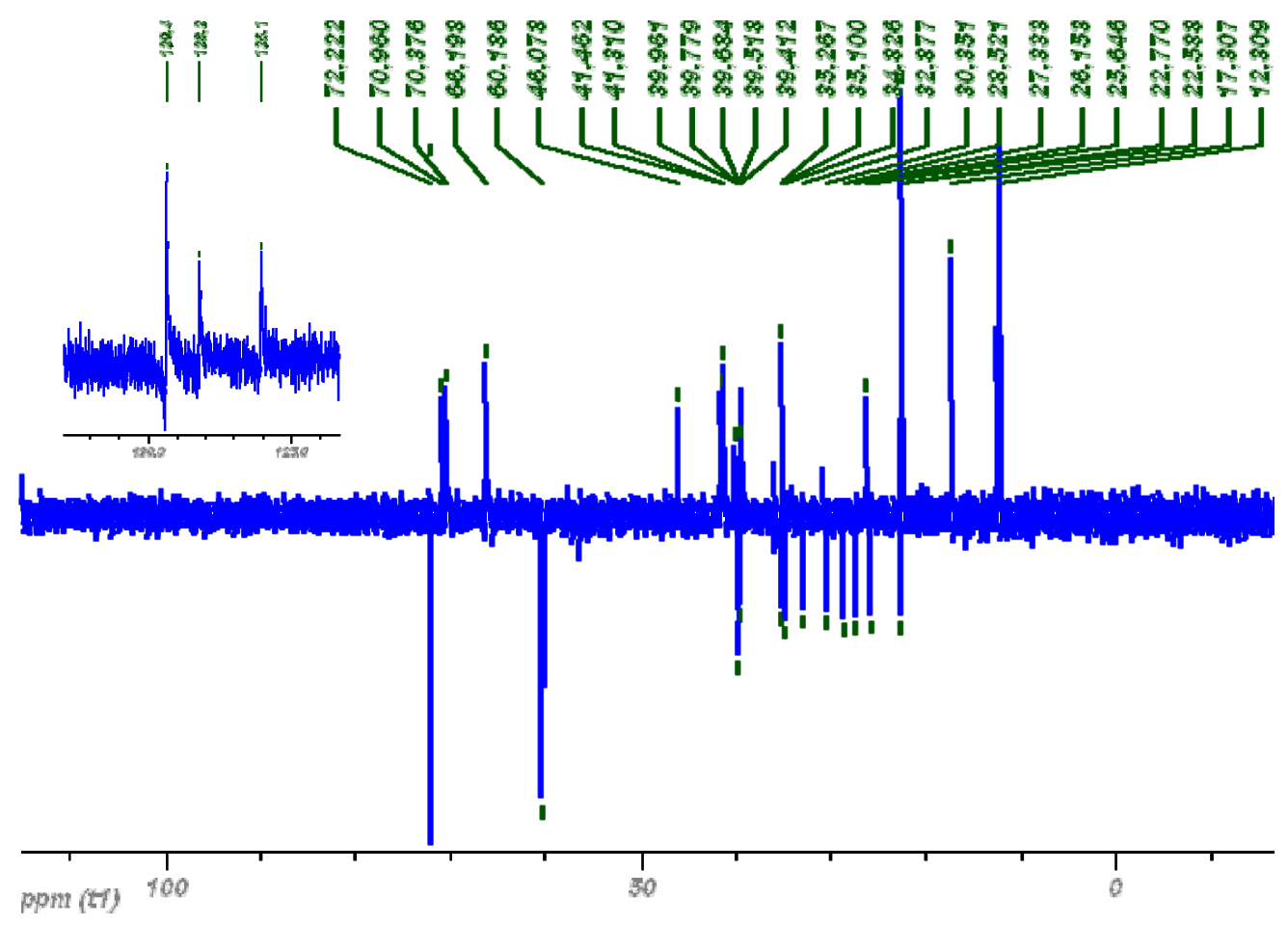

Figure 7.- DEPT- 135 spectrum of $\underline{8}$ in DMSO- $\mathrm{d}_{6}$. 


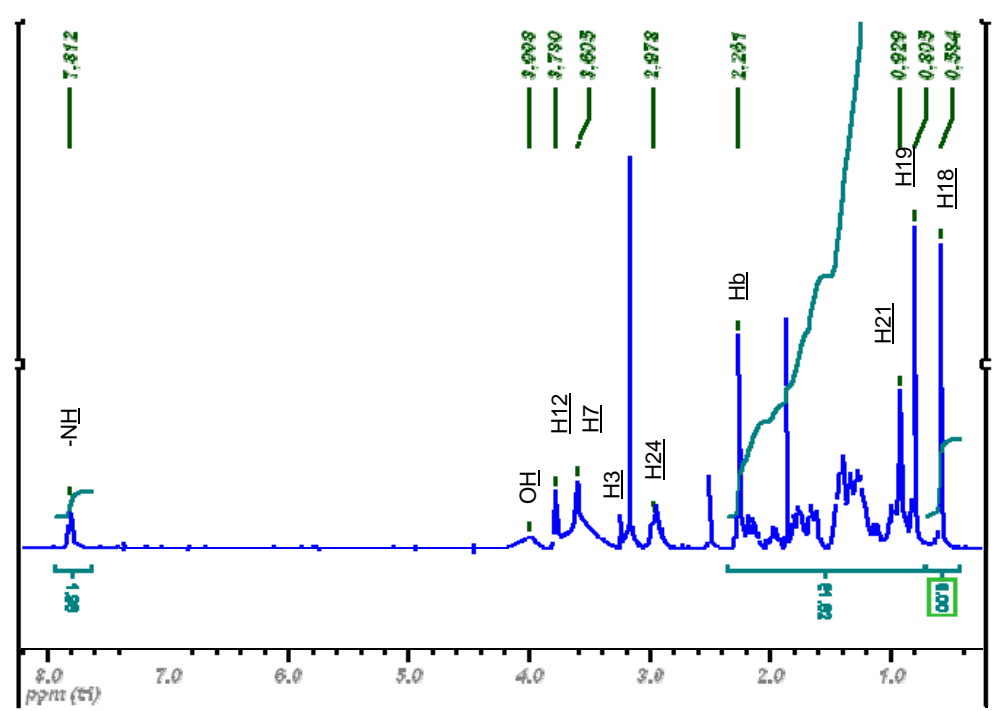

Figure 8.- ${ }^{1} \mathrm{H}-\mathrm{NMR}$ spectrum of $\underline{11}$ in DMSO- $\mathrm{d}_{6}$.

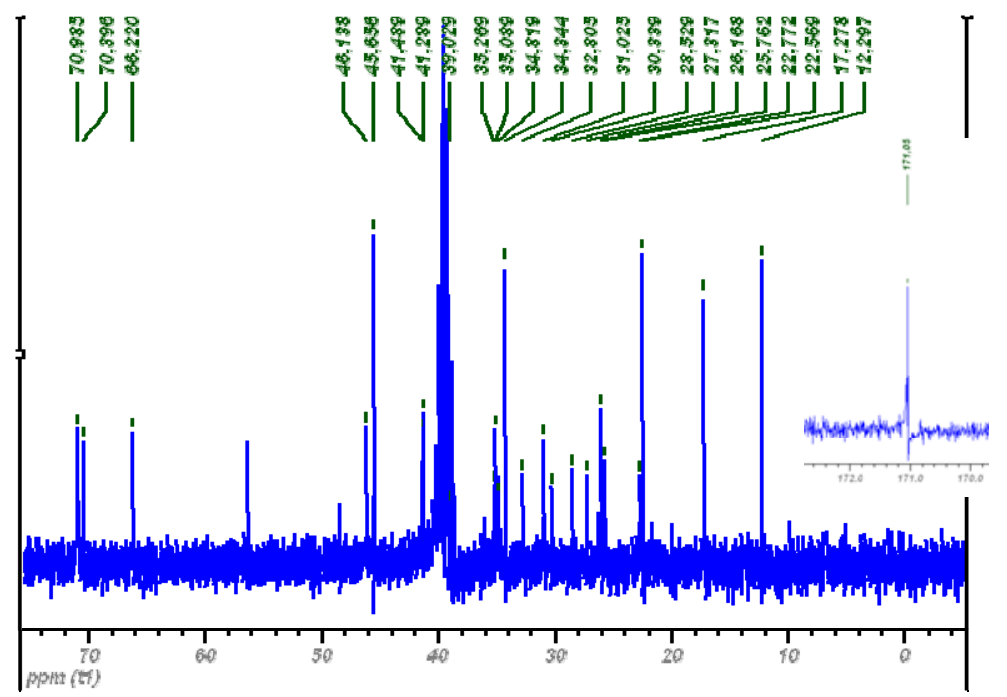

Figure 9.- ${ }^{13} \mathrm{C}-\mathrm{NMR}$ spectrum of $\underline{11}$ in DMSO- $\mathrm{d}_{6}$. 


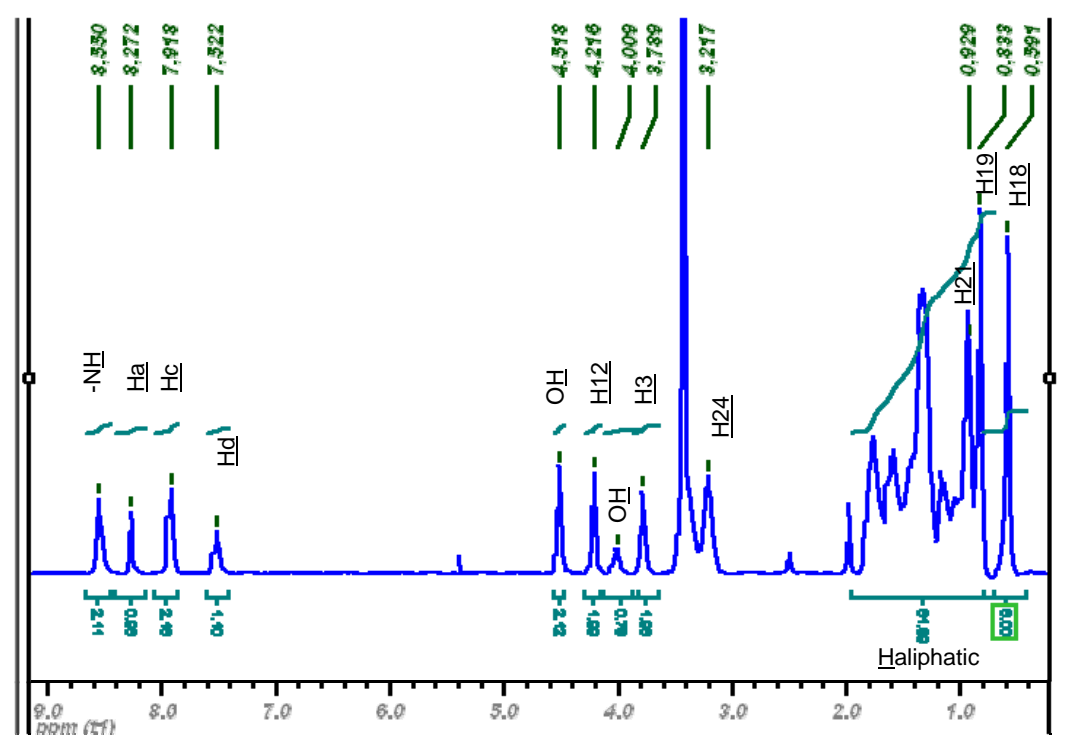

Figure 10.- ${ }^{1} \mathrm{H}-\mathrm{NMR}$ spectrum of $\underline{9}$ in DMSO- $\mathrm{d}_{6}$.

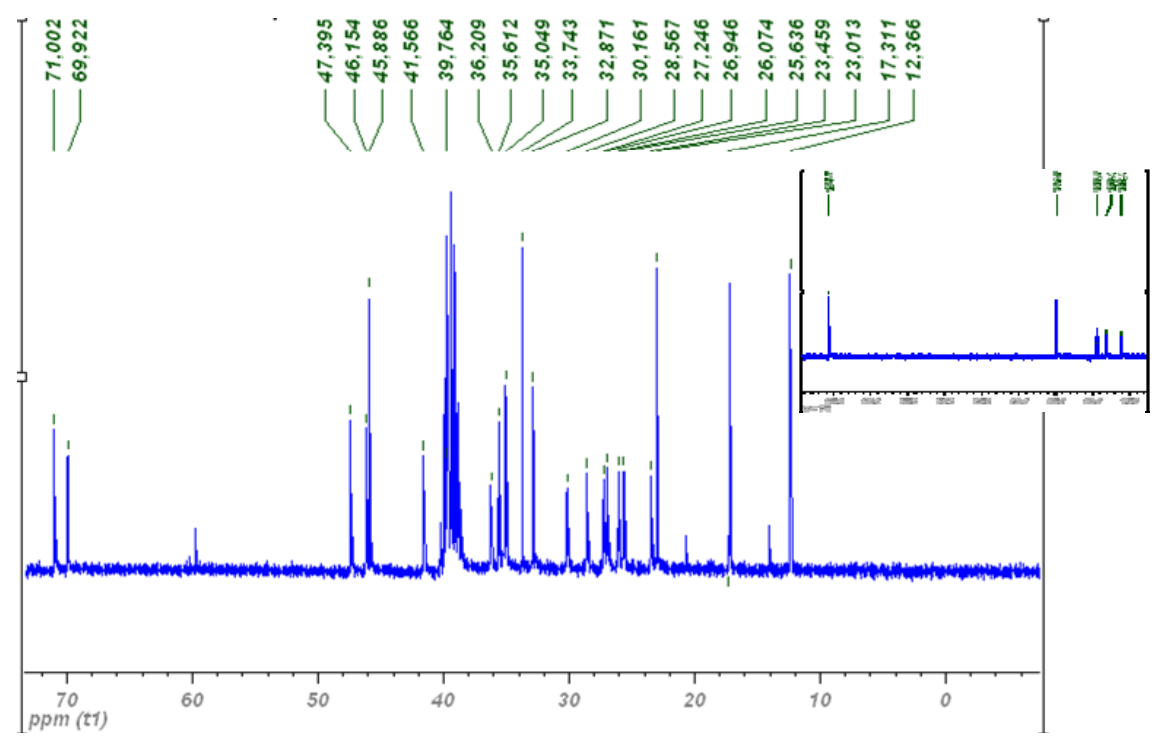

Figure 11.- ${ }^{13} \mathrm{C}-\mathrm{NMR}$ spectrum of $\underline{9}$ in DMSO- $\mathrm{d}_{6}$. 


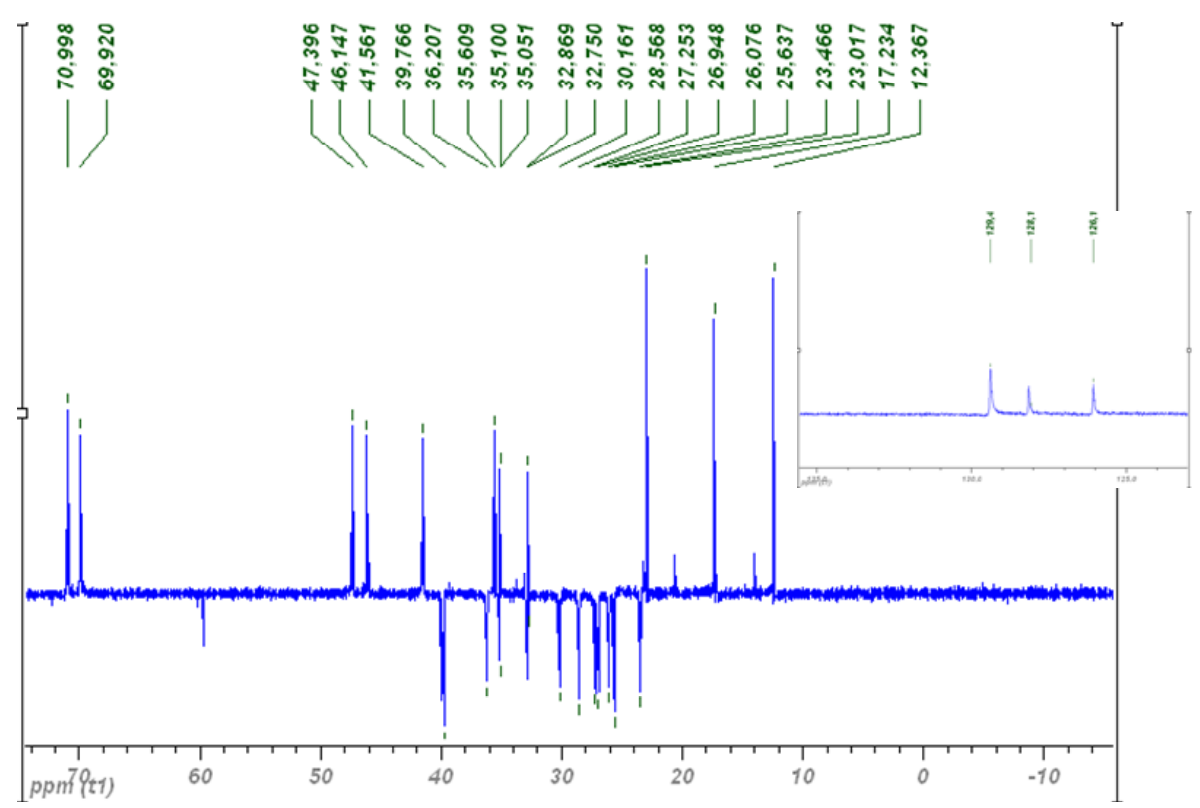

Figure 12.- DEPT-135 spectrum of $\underline{9}$ in DMSO-d 6 .

\section{Conclusions}

Dimeric steroid-based surfactants $\underline{8}-\underline{11}$ have been satisfactorily synthesized and structurally characterized by NMR techniques.

Acknowledgments. Authors thank the Ministerio de Ciencia y Tecnología (Project MAT200404606) and the Xunta de Galicia (PGIDIT05PXIC26201PN) for financial support. 